\title{
Editorial
}

\section{Epidemias: ¿se puede aprender algo de ellas?}

La historia moderna de Colombia comienza en medio de grandes epidemias. Entre 1500 y 1617, la población indígena de la Nueva Granada, la actual Colombia, bajó, según cálculos aproximados, más o menos un 90 \%." En total, tal vez unos 4 millones de personas murieron. Las descripciones de la época muestran el terror que producían estas enfermedades, vistas en gran parte como expresión de la cólera de Dios. La respuesta fue una combinación de medidas de prevención (confinamientos de algunos viajeros, prohibición de entrar a algunas partes), higiene y religión: en 1588 se sacó la imagen de la Virgen de Chiquinquirá, recién descubierta, de Chiquinquirá a Tunja, para hacer rogativas que buscaban frenar una epidemia de viruela en la que, según Pedro Simón [4], murió el $30 \%$ de la población nativa. *

Los historiadores de la medicina ${ }^{\S}$ han tratado de aclarar qué enfermedades eran. En general, están de acuerdo con que hubo grandes epidemias de viruela en 1558, 1578, 1617, 1782 y 1802. Las epidemias de tifo, disentería, fiebre amarilla o malaria, y sobre todo de influenza o gripe, son más debatidas: las descripciones son insuficientes para hacer un diagnóstico confiable. Así, por ejemplo, hacia 1560, una epidemia acabó casi por completo con la población nativa de Valledupar y Tenerife. Se caracterizó por fiebres, dolores de garganta y ahogamientos. Probablemente, dicen los historiadores, una influenza. Pero murieron también los animales de monte, que suponemos inmunes a estos virus. Quizá murieron de otra cosa: la epidemia coincidió con una peste de langostas, que acabó con la comida. ${ }^{* *}$ En 1633, una gran peste de tifo ("tabardillo" es el nombre de la época) hizo que de nuevo la Virgen de Chiquinquirá fuera conducida a Bogotá, donde el arzobispo murió, y también a Tunja.

A fines del siglo xviII, los avances científicos de la medicina eran claros, y en la epidemia de 1782, aunque el virrey era un arzobispo, la Virgen de Chiquinquirá no salió de su santuario, y se aplicó la inoculación del virus que se había ensayado en Cartagena hacia 1756. El mayor peso de la ciencia se confirmó a partir de 1803, cuando se aplicó la vacuna: la elección entre religión y prevención llevó en general a graduar las dosis de cada remedio, confiando más, para su prevención en este mundo, en el conocimiento y las medidas preventivas.

Sin embargo, las epidemias continuaron. Sirvieron para defender a los habitantes locales, como en 1740, contra Vernon en Cartagena, y entre 1816 y 1819 contra Pablo Morillo. Pero a partir de 1830, ya en la República, las preocupaciones de los gobernantes se ampliaron, pues a la salud y la religión se añadió la economía. En la epidemia de 1850, de cólera, se aprobó una ley para prohibir los confinamientos y el cierre de puertos, pues esto perjudicaba a los comerciantes y a los artesanos. Un congresista ${ }^{\dagger \dagger}$ argumentó, para apoyar esta prohibición, que no debía impedirse la extensión de la epidemia, pues era un castigo de Dios por los pecados de los neogranadinos. Mientras tanto, los médicos y muchas autoridades locales pedían la cuarentena.

Y en 1918, la epidemia de influenza fue enfrentada con medidas de salud pública. En Bogotá, donde fue más fuerte, se creó una junta de salud pública, que organizó todo: las estadísticas, que se daban diariamente, así como los

* La discusión acerca de las cifras de población indígena y su evolución ha sido larga. En 1976, en Historia de Colombia: el establecimiento de la dominación española, calculé que esa población era de unos 5 millones en 1500, y entre 1535 y 1560, de 4 millones de habitantes [1, pp. 107-116]. Hacia 1560 se habían reducido a 1200000 y siguió bajando hasta 1700 cuando, según los cálculos más recientes de Tovar, debió ser de un poco más de 500000 habitantes [2]. Véase también "Población, enfermedad y cambio demográfico, 1537-1560", de Michael Francis [3].

† Por ejemplo, se encuentran descripciones en Bartolomé de las Casas [4], Gonzalo Fernández de Oviedo [5], Pedro de Aguado [6], Pedro Simón [7] y en muchos otros cronistas, como Cieza de León, Zamora, Vargas Machuca, etc. También hay descripciones en diversos documentos de la época, como los publicados por Juan Friede [8,9].

* Sobre esta epidemia y la salida de la Virgen, tienen narraciones Juan Rodríguez Freyle [10], así como Pedro Simón [7, tomo IV, Séptima Noticia, Capítulo XXXIX].

$\S \quad$ Los estudios clásicos para la conquista americana son los de William McNeill [11] y Alfred Crosby [12]. Puede complementarse y actualizarse con Francisco Guerra [13] y Noble David Cook y William George Lovell [14]. Sobre la Nueva Granada, los estudios más conocidos son el de Pedro María Ibáñez [15], Andrés Soriano Lleras [16] y Emilio Quevedo et al. [17].

** La epidemia de Valledupar y Tenerife está descrita en Bartolomé Briones de Pedraza et al. [18] y en Bartolomé de Aníbal Paleólogo et al [19].

$\dagger \dagger$ Fernando Serpa Flórez [20] transcribe parte de los discursos de Manuel María Mallarino, enemigo de la cuarentena, y de Domingo Arosemena, médico panameño que la apoyaba. 
entierros y las autopsias, para lograr un diagnóstico confiable. Murieron, en el país, unas 5000 personas que, aunque son muchas (equivalen, en la población actual, a unos 50000 muertos), eran mucho menos que en las de las epidemias coloniales [21-24]. La ciencia parecía haber triunfado, y en el resto del siglo muchas enfermedades que tenían brotes epidémicos se fueron controlando más y más: la viruela, el sarampión, el tifo y eventualmente el polio. La malaria, que también, como la viruela, había llegado con los españoles, se redujo con una campaña que usó el dicloro difenil tricloroetano (DDT), y que eventualmente se suspendió.

Las autoridades de salud, en todo caso, no parecen haber previsto algo como la epidemia reciente: al comenzar esta hace unos meses, no existían sistemas definidos de antemano para hacer pruebas y diagnósticos, publicar estadísticas comparables y confiables. En esto, Colombia estaba tan desprevenida como los países avanzados, a los que también cogió por sorpresa. Y volvió a repetirse el problema ético: cómo medir y balancear los efectos sobre la salud y la economía; cómo pesar los muertos por la enfermedad y los males del hambre, el desempleo y eventualmente otras muertes, menos calculables.

Peter Singer, por ejemplo, ha argumentado que hay que ser capaz de decidir que mueran algunos del virus, para que los males indefinidos de la economía no se propaguen [25]. Otros hacen ver que los muertos causados por el coronavirus son más o menos definibles (morirán unos centenares o miles de personas en Colombia, por ejemplo), pero, aunque habrá desempleo, no pueden achacárseles, a quienes apoyan un retorno inmediato a la actividad económica completa, las muertes que habrá en uno o dos años: se trata de elegir la muerte de algunos, más o menos predecibles (los ancianos, los médicos mal protegidos) para evitar unos males cuya gravedad es hipotética y difusa. Y, por supuesto, no se trata de escoger entre la salud y la economía, en un dilema binario, de cero o uno, sino de graduar las medidas que tratarán de responder, con diferentes pesos y resultados, a ambas preocupaciones. Todos están de acuerdo con salvar vidas, y la discusión es cómo ser más eficiente, cómo lograr que las medidas preventivas no resulten muy costosas, por sus efectos sobre la economía.

Esto apunta a un problema de fondo de los sistemas de debate, discusión y decisión de la democracia: no hay un buen procedimiento para balancear los diferentes intereses y las distintas perspectivas. Muchos políticos reflejan sobre todo la presión de los grupos económicos, que se preocupan ante todo por las caídas eventuales del producto interno bruto, por los hoteles vacíos o las ventas de carros, o la inquietud de corto plazo de personas que pierden su trabajo y pasan a depender del apoyo público. Otros están atentos al efecto electoral de la crisis. Y casi nadie tiene, porque esto no se tenía previsto, buenos sistema de información: apenas en este momento se está discutiendo cómo contar los fallecidos en España o Italia, o cómo definir cuándo se llega al pico de inflexión del contagio: ¿cuándo comienzan a caer los casos nuevos, o los decesos? ¿Cuándo la curva descendente se confirma: con un promedio móvil o en el primer momento en que empieza a bajar? Apenas hace pocos días se empezaron a publicar datos históricos de contagios para casi todos los países, día a día. El número $\mathrm{R}_{\mathrm{o}}$ nunca tuvo un sentido preciso (el número de personas que un enfermo contagia, sin definir tiempo: ¿en un día, en una semana, en un mes?). Y los problemas burocráticos, la disponibilidad de reactivos y el tiempo del diagnóstico hacen que los datos requeridos sobre el número de contagiados no lleguen o estén alterados por razones externas: muchos países tienen pocos enfermos, pero es porque no hacen pruebas; o pocos muertos, pero es porque los clasifican en otro grupo. El dato de recuperados no debe de haber servido para nada: es una información para tranquilizar a la gente, como las especulaciones de los medios y de algunos funcionarios sobre una eventual vacuna, a la que no se le puede poner fecha.

Por supuesto, gran parte de la incertidumbre de los funcionarios tiene que ver con las insuficiencias del conocimiento: todavía no se sabe cuánto puede durar la inmunidad de los que se han curado, ni cuáles son las situaciones de la vida diaria en la que los contagios son más posibles (¿cruces callejeros, ciclovías, almuerzos en restaurantes, clases universitarias?) o la distancia en la que el virus no se trasmite por el aire. Por eso, el regreso al trabajo está lleno de incertidumbres $\mathrm{y}$, en el fondo, es imposible calcular cuántas vidas salvará una medida dura ni cómo afectará el empleo y el ingreso y, por lo tanto, cuántas vidas se perderán a la larga por sus efectos futuros.

De todos modos, la epidemia deja algunas conclusiones. La primera es que, en estos casos, la solidaridad crece mucho: muchos empresarios, por ejemplo, buscaron cómo seguir pagando a sus empleados, y aceptaron medidas económicas que por su efecto sobre el déficit o los impuestos siempre rechazaban. Sin embargo, hay que buscar cómo hacer que las discusiones hagan más explícitas las opciones, los efectos de conductas solidarias o egoístas: la epidemia ha mostrado que la salud es un bien social, y que los que buscan su propia salud pueden a la larga perderla, por no atender a la de los demás. Si el trasporte público es un medio de contagio grave, se enfermarán no solo los que lo usan, y lo mismo va a pasar con el trabajo en fábricas y almacenes.

En segundo lugar, y para hacer más efectivas las medidas de salud pública, además, hace falta tomar mucho más en serio los sistemas de información y de análisis, muy sometidos a los intereses de imagen de las organizaciones internacionales, de los gobiernos y de los profesionales. $\mathrm{O}$ se hallan muy trabados por dificultades burocráticas: la falta de pruebas parece haber tenido una influencia desmedida en la evaluación de los avances de la epidemia, y no hay buenas 
hipótesis para explicar por qué países como India, Pakistán o Indonesia han tenido tan pocos contagios y tan pocas muertes, o por qué las tasas más altas de casos y muertes por habitantes corresponden a países como Suiza, Bélgica o Luxemburgo. Sería bueno que entidades independientes, como grupos de universidades o centros de investigación, se alíen para hacer el seguimiento y el análisis de los datos, para crear sitios de información estadística, de cálculo diario de las tasas de crecimiento de la epidemia, de análisis de las correlaciones entre el número de muertes y otros factores de un país o una región. Pero esto puede requerir creer organismos representativos de diversos sectores que se encarguen de recomendar las políticas, en caso de emergencias, de manera que las decisiones no las tomen políticos empeñados en ganar una elección o conseguir el apoyo de los grandes inversionistas.

Puede ser prematuro, pero hasta ahora, 20 de abril de 2020, da la impresión de que le ha ido mejor a los países que tomaron en serio la amenaza, que no la minimizaron y actuaron con rapidez, y que tenían un sistema razonable de salud pública. Y esto puede confirmar la otra gran concusión: que la prevención es, por principio, el mejor tratamiento.

DOI: https://doi.org/10.17533/udea.rfnsp.e341912

Jorge Orlando Melo Historiador.

\section{Referencias}

1. Melo JO. Historia de Colombia: el establecimiento de la dominación española. Bogotá: La Carreta; 1977.

2. Tovar H. Las cifras y los métodos en la reconstrucción de la población colombiana. En: Meisel Roca A. y Ramírez MT, editores. La economía colonial de la Nueva Granada. Bogotá: Banco de la República, Fondo de Cultura Económica; 2015.

3. Francis MJ. Población, enfermedad y cambio demográfico, 1537-1560. En: Gómez AM, editora, Muiscas: representaciones, cartografías y etnopolíticas de la memoria. Bogotá: Universidad Javeriana, 2005. pp. 74-151.

4. Casas, B de las. Historia de las Indias. 3 vols. México: Fondo de Cultura Económica; 1951.

5. Fernández de Oviedo G. Historia general y natural de las Indias: islas y tierra-firme del mar océano. 4 vols. Madrid: Real Academia de la Historia; $1851-1855$.

6. Aguado P de. Recopilación historial. 4 vols. Bogotá: Biblioteca de la Presidencia de la República, Empresa Nacional de Publicaciones; 19561957.

7. Simón P. Noticias historiales de las conquistas de Tierra Firme en las Indias occidentales. 4 vols. Bogotá: Biblioteca Banco Popular; $1980-1981$.

8. Friede J. Documentos inéditos para la historia de Colombia. 10 vols. Bogotá: Academia Colombia de la Historia; 1955-1960.

9. Friede J. Fuentes documentales para historia del Nuevo Reino de Granada desde la instalación de la Real Audiencia de Santafé. 8 vols. Bogotá: Biblioteca Banco Popular; 1975-1976.

10. Freyle JR, El Carnero. Bogotá: Instituto Caro y Cuervo, 1977.

11. McNeill W. Plagues and Peoples. Nueva York: Anchor Books Doubleday; 1978.

12. Crosby AW. The Columbian Exchange. Biological and Cultural Consequences of 1492. Westport (Conn., EE. UU.): Greenwood Press; 1973.

13. Guerra F. Epidemiología americana y filipina (1492-1898). Madrid: Ministerio de Sanidad y Consumo, 1999.

14. Cook DN, Lovell WG, editores. Juicios secretos de Dios. Epidemias y despoblación indígena en Hispanoamérica colonial. Quirto: Abya Yala; 2000.

15. Ibáñez PM. Memorias para la historia de la medicina en Santafé de Bogotá. Bogotá, 1884.

16. Soriano Lleras A. La medicina en el Nuevo Reino de Granada: durante la Conquista y la Colonia. Bogotá: Kelly; 1972.

17. Quevedo E et. al. Historia de la medicina en Colombia. 4 tomos. s. 1. Tecnoquímicas; 2008.

18. Briones de Pedraza B, et al. Relacion de Tenerife II. Cespedesia. 1983;(Suplemento 4, 45 y 46):153-76.

19. Aníbal Paleólogo B de, et al. Relación de los Reyes del Valle de Upar (1580). Cespedesia. 1983;(Suplemento 4, 45 y 46):193-213.

20. Serpa Flórez F. Historia del cólera en Colombia. Biomédica. 1992;12(3-4):95-101. DOI: https://doi.org/10.7705/biomedica.v12i3-4.2031

21. Carvajal JF, Martínez-Martín AF, et al. La pandemia de gripa de 1918 en Bogotá. Aproximación histórico-epidemiológica. Perspectiva. 2006;13(1):19-32.

22. Manrique-Abril FG, Martínez-Martín AF, et al. La pandemia de gripe de 1918-1919 en Bogotá y Boyacá, 91 años después., Revista Infectio. 13(3):182-91.

23. Crosby AW. America's Forgotten Pandemic: The Influenza of 1918. Cambridge: Cambridge University Press; 2003.

24. Martínez Martín AF, Manrique Abril FG, Meléndez Álvarez BF. La pandemia de gripa de 1918 en Bogotá. Dynamis. 2007;(27):287-307.

25. Singer P. Entrevista con Jorge Fontevecchia. "Peter Singer: 'Si hay más muertos por pobreza que por coronavirus, la cuarentena sería un error". Perfil. 2020 may. 2. https://www.perfil.com/noticias/periodismopuro/si-hay-mas-muertos-por-pobreza-que-por-coronavirus-la-cuarentena-seria-un-error.phtml 